\title{
COMPARAÇÃO ENTRE O MÉTODO CULTURAL CLÁSSICO E O BIND TEST RÁPIDO PARA PESQUISA DE Salmonella sp EM ALIMENTOS
}

\author{
GISLENE MARI FUJIWARA * \\ ANELISE TALAMINI ** \\ MARCIA REGINA BEUX ***
}

\begin{abstract}
Este trabalho teve por objetivo avaliar dois métodos para a pesquisa de Salmonella sp em alimentos. O projeto foi dividido em duas etapas: a primeira, realizada com cepas padrão, visou a verificação da especificidade dos métodos, enquanto a segunda comparou os resultados obtidos. Os métodos utilizados foram o cultural clássico, indicado pela Association of Official Analytical Chemists (AOAC), pela Food and Drug Administration (FDA) e pela legislação brasileira e o BIND test rápido, ainda não citado como método usual, mas já aceito pela AOAC. Os resultados demonstraram que não há diferença entre os métodos, ficando a escolha de utilização a critério dos laboratórios.
\end{abstract}

\section{INTRODUÇÃO}

O gênero Salmonella é constituído por várias espécies de bacilos Gramnegativos da família Enterobacteriaceae, que fermentam glicose, com produção de gás e normalmente não fermentam lactose nem sacarose (1).

As salmoneloses são infecções bacterianas de origem alimentar, decorrentes da ingestão de células viáveis presentes em alimentos contaminados, principalmente carnes e ovos (6).

* Aluna do Curso de Farmácia e Bioquímica, Pontifícia Universidade Católica do Paraná (PUC-PR), Estagiária do Laboratório de Microbiologia de Alimentos e Águas, Centro de Pesquisa e Processamento de Alimentos (CEPPA).

* Bióloga responsável pelo Laboratório de Microbiologia de Alimentos e Águas, CEPPA.

*** Mestre em Tecnologia de Alimentos, Coordenadora do Laboratório de Alimentos, CEPPA. 
Devido aos riscos que apresenta aos seres humanos, a Salmonella é considerada pela legislação brasileira vigente, pela Food and Drug Administration (FDA), pelo United States Department of Agriculture (USDA) e pela Association of Official Analytical Chemists (AOAC) como microrganismo de "tolerância zero". Desta forma, recomenda-se que o fabricante de alimentos tome medidas para assegurar que não sejam detectadas células de Salmonella em seu produto final (2).

Para pesquisa de Salmonella sp em alimentos, o método recomendado pelo Bacteriological Analytical Manual (BAM) e pela American Public Health Association (APHA) é o método cultural clássico, desenvolvido com a finalidade de garantir a detecção deste microrganismo, mesmo em alimentos que apresentem situações extremamente desfavoráveis para o desenvolvimento do mesmo. É o caso de alimentos com microbiota competidora muito maior que a população de Salmonella, alimentos em que as células se encontrem em número muito reduzido e/ou alimentos em que as células se encontrem injuriadas pelo processo de preservação, como a aplicação de calor, congelamento e/ou secagem $(3,8)$. Este método pode ser dividido em quatro etapas (pré-enriquecimento, enriquecimento, em caldo seletivo, plaqueamento seletivo diferencial e confirmação), podendo ocorrer em cada uma delas variações na seleção dos meios de cultura e na forma de preparação das amostras, dependendo da natureza do alimento a ser analisado (5).

O pré-enriquecimento objetiva recuperar as células de Salmonella que, normalmente estão presentes em pequenas quantidades e em condições debilitadas nos alimentos processados (6). O enriquecimento em caldo seletivo objetiva inibir a multiplicação da microbiota acompanhante e promover a elevação preferencial do número de células de Salmonella, incubando-se a amostra pré-enriquecida em caldo seletivo por 18 a 24 horas. Nesta etapa, recomenda-se a utilização de dois diferentes meios, pois a resistência da Salmonella aos agentes seletivos varia de cepa para cepa. O plaqueamento seletivo diferencial visa promover o desenvolvimento preferencial de colônias de Salmonella, com características típicas que as distinguam dos competidores, para posterior confirmação bioquímica e sorológica. Assim como na etapa de enriquecimento, recomenda-se a utilização de pelo menos dois meios distintos para o plaqueamento. Mediante provas bioquímicas e sorológicas pode-se confirmar se as colônias típicas obtidas nas placas são realmente colônias de Salmonella (4).

Uma nova metodologia para a pesquisa de Salmonella surgiu com a finalidade de reduzir o tempo requerido de análise pelo método cultural clássico. O BIND test rápido destina-se a triagem de amostras positivosuspeitas ou negativas para Salmonella em 24 horas ou menos, a partir de um único pré-enriquecimento. A obtenção de resultado negativo no teste 
indica que a amostra é negativa para Salmonella e o resultado positivo deve ser confirmado mediante métodos padronizados de identificação. O principal reagente utilizado pelo BIND é a mistura de bacteriófagos, modificados geneticamente para carregar gen capaz de induzir a produção de proteína na célula da Salmonella. Quando o vírus ataca uma célula de Salmonella, seu material genético é liberado em seu interior, induzindo-a a produzir proteína específica. Em presença desta proteína, a amostra congela rapidamente quando submetida a temperatura de $-9,3{ }^{\circ} \mathrm{C}$. A amostra congelada adquire cor laranja, devido à presença de indicador. Amostras que não contém a proteína específica têm seu congelamento inibido. Os bacteriófagos presentes no BIND são específicos para o gênero Salmonella, por esta razão o BIND trabalha com alta sensibilidade e especificidade. Os fagos utilizados pelo BIND Salmonella detectam grande variedade de sorotipos, incluindo os mais comumente encontrados nos alimentos (5).

Este trabalho teve por objetivo comparar a eficiência de dois métodos para pesquisa de Salmonella em alimentos, o método cultural clássico e o BIND test rápido.

\section{MATERIAL E MÉTODOS}

Para avaliação dos métodos utilizados para pesquisa de Salmonella, o projeto foi dividido em duas etapas. Na primeira verificou-se a seletividade dos métodos, trabalhando com biscoito estéril, contaminado artificialmente com cepas padrão de microrganismos (Staphylococcus aureus, Enterobacter aerogenes, Escherichia coli, Citrobacter freundii e Salmonella enteritidis) isolados ou misturados a cepa de salmonela. Analisou-se também uma amostra de água peptonada tamponada estéril, uma amostra de caldo tetrationato estéril e uma amostra de biscoito sem contaminação, totalizando nove amostras.

As análises foram realizadas em duplicata e as cepas reativadas, inoculando-se uma alçada de cada microrganismo, mantido em ágar nutriente, em tubos contendo caldo BHI (infuso de cérebro e coração), os quais foram incubados por 24 horas em estufa a $35^{\circ} \mathrm{C}$.

Das sete amostras de biscoito utilizadas, cinco foram contaminadas respectivamente com as cepas Staphylococcus aureus, Enterobacter aerogenes, Escherichia coli, Citrobacter freundii e Salmonella enteritidis, uma com mistura das cepas contendo a da salmonela e uma com mistura das cepas excetuando-se a da salmonela. Cada uma das sete amostras foi homogeneizada com $225 \mathrm{~mL}$ de caldo lactosado e posteriormente contaminada com as cepas padrão. Todas as amostras, inclusive as de 
água peptonada tamponada e de caldo tetrationato foram incubadas a $35^{\circ} \mathrm{C}$. Após $18-24$ horas, $1 \mathrm{~mL}$ de cada amostra foi transferido para tubos contendo caldo selenito-cistina e para tubos contendo caldo tetrationato enriquecido com solução de verde-brilhante e solução de iodo. Nesta etapa, as amostras foram inoculadas em duplicata e os tubos incubados por 18-24 horas a $35{ }^{\circ} \mathrm{C}$. Em seguida, as amostras foram semeadas em placas de Petri contendo ágar entérico de Hecktoen (HE) e ágar xilose lisina desoxicolato (XLD), sendo incubadas por 18 a 24 horas a $35^{\circ} \mathrm{C}$. As colônias que se desenvolveram nos meios foram repicadas para ágar tríplice açúcar - ferro (TSI) e para ágar lisina ferro (LIA). A identificação das colônias repicadas foi obtida mediante kit para identificação de enterobactérias, que contém as seguintes provas bioquímicas: desaminação do L-triptofano, fermentação da glicose, produção de $\mathrm{H}_{2} \mathrm{~S}$, descarboxilação da lisina, descarboxilação da ornitina, produção de indol, motilidade, utilização do citrato e fermentação da rhamnose e da lactose (3).

Para o BIND test rápido utilizou-se o kit para testes contendo tubos de reação (rosa) e tubos de background (branco), além de bandejas para amostra, adesivos para fechamento das bandejas e congelador portátil. Neste método, as amostras foram incubadas por 18-24 horas em estufa bacteriológica, após homogeneização com $225 \mathrm{~mL}$ de água peptonada tamponada, segundo o mesmo esquema de contaminação utilizado pelo método cultural clássico. Após diluição 1:10 em água peptonada tamponada foram retiradas duas alíquotas de $0,5 \mathrm{~mL}$, sendo a primeira depositada em tubos de background e a segunda em tubos de reação. Após 2,5 horas de repouso, 8 cavidades da bandeja foram preenchidas com as amostras dos tubos de reação (cada amostra de $50 \mu \mathrm{L}$ deve preencher uma série de 8 cavidades). Selada com adesivo próprio, a bandeja foi levada ao congelador com temperatura de $-9,3{ }^{\circ} \mathrm{C}$ por 20 minutos. Verificou-se então a presença de coloração laranja de acordo com o seguinte esquema:

- havendo congelamento de uma cavidade, ou de nenhuma, a amostra é considerada negativa e o tubo de background pode ser descartado;

- se 2 ou mais cavidades congelarem, para cada amostra, esta será considerada positivo-suspeita. $\mathrm{O}$ tubo de background deve ter seu conteúdo transferido para bandeja de amostra e resfriado para avaliação. Após resfriamento do conteúdo do tubo de background, os resultados obtidos devem ser comparados com aqueles provenientes do tubo de reação da mesma amostra. Após comparação o resultado é considerado positivo se o número de cavidades congeladas para a amostra do tubo background for menor que o número de cavidades congeladas da amostra proveniente do tubo de reação. 
A amostra é considerada negativa de forma confirmativa se o número de cavidades congeladas provenientes do tubo de background for maior do que as provenientes do tubo de reação, para uma dada amostra. Para as amostras positivas obtém-se a confirmação pelo método cultural clássico, fazendo-se a identificação com provas bioquímicas (5).

Na segunda etapa foram semeadas oito amostras de farinha de trigo, uma de carne moída, uma de lingüiça, uma de ovo em pó e uma de ovo com casca, totalizando doze amostras. Todas as doze amostras foram submetidas simultaneamente aos dois métodos, visando comparação dos resultados obtidos em ambos. Os procedimentos analíticos foram os mesmos adotados para a primeira etapa, sendo realizados em câmara de fluxo laminar, atrás de chama e com materiais estéreis.

\section{RESULTADOS E DISCUSSÃO}

\subsection{ETAPA 1}

Como a amostra a ser utilizada para os testes com as cepas padrão não poderia conter microrganismos que pudessem interferir nas análises comprovou-se sua inocuidade mediante pesquisa de bactérias mesófilas, fungos e enterobactérias.

Na Tabela 1 estão apresentados os resultados obtidos na primeira etapa, que corresponde a avaliação da capacidade de recuperação, seleção e diferenciação do método cultural clássico em relação ao BIND test, para as amostras previamente contaminadas. Comprovou-se, mediante provas bioquímicas que todas as colônias selecionadas (de acordo com a seletividade dos meios) pertenciam às cepas padrão iniciais.

Comparando-se os resultados obtidos observa-se que, não há diferença quanto a identificação bioquímica das colônias isoladas, caracterizando que ambos métodos permitem a mesma eficiência de recuperação.

A seletividade do método cultural clássico é devida a adição de componentes na formulação que retardam ou impedem o desenvolvimento de alguns grupos de microrganismos. Os caldos selenito e tetrationato apresentam substâncias que inibem o desenvolvimento de bactérias Gram positivas. O ágar entérico de Hecktoen $(\mathrm{HE})$ e o ágar xilose lisina desoxicolato (XLD) apresentam alta concentração de sais de bile, que também inibem o desenvolvimento de bactérias Gram positivas, favorecendo o crescimento de células de Salmonella. 


\section{TABELA 1 - RESULTADOS OBTIDOS PELO MÉTODO CULTURAL CLÁSSICO E PELO BIND TEST EM AMOSTRAS CONTAMINADAS (ETAPA 1)}

\begin{tabular}{l|c|c|c}
\hline \multicolumn{1}{c}{$\begin{array}{c}\text { Método Cultural } \\
\text { Clássico }\end{array}$} & \multicolumn{2}{c}{ BIND Test } \\
\hline Amostras & Identificação bioquímica & Triagem & $\begin{array}{c}\text { Identificação } \\
\text { Bioquímica }\end{array}$ \\
\hline Cepa de S. aureus & $\begin{array}{c}\text { Ausência de colônias nos } \\
\text { meios HE* e XLD** }\end{array}$ & 0 (NEGATIVO) & ----------------------- \\
\hline Cepa de E. aerogenes & Enterobacter aerogenes & 0 (NEGATIVO) & ----------------------- \\
\hline Cepa de C. freundii & Citrobacter freundii & $3 / 0$ (POSITIVO) & Citrobacter freundii \\
\hline Cepa de E. coli & Escherichia coli & 0 (NEGATIVO) & ----------------------- \\
\hline Cepa de S. enteritidis & Salmonella enteritidis & $8 / 0$ (POSITIVO) & Salmonella enteritidis \\
\hline $\begin{array}{l}\text { Mistura das cepas c/ } \\
\text { Salmonella }\end{array}$ & $\begin{array}{c}\text { Enterobacter aerogenes } \\
\text { Salmonella enteritidis }\end{array}$ & $8 / 0$ (POSITIVO) & $\begin{array}{c}\text { Enterobacter } \\
\text { aerogenes }\end{array}$ \\
\hline $\begin{array}{l}\text { Mistura de cepas } \\
\text { s/Salmonella }\end{array}$ & $\begin{array}{c}\text { Enterobacter aerogenes } \\
\text { Citrobacter freundii }\end{array}$ & $8 / 1$ (POSITIVO) & Salmonella enteritidis \\
\hline Água peptonada & $\begin{array}{c}\text { Ausência de colônias nos } \\
\text { meios HE e XLD }\end{array}$ & 0 (NEGATter \\
aerogenes \\
\hline Caldo Tetrationato & $\begin{array}{c}\text { Ausência de colônias nos } \\
\text { meios HE e XLD }\end{array}$ & 0 (NEGATIVO) & ------------------------ \\
\hline
\end{tabular}

* $\mathrm{HE}=$ Ágar entérico de Hecktoen

** XLD = Ágar xilose lisina desoxicolato.

As amostras são positivo-suspeitas para a pesquisa de Salmonella quando há desenvolvimento de colônias nos meios de isolamento com características específicas. No ágar entérico de Hecktoen há o desenvolvimento de colônias transparentes, verde-azuladas, com ou sem centro preto e no ágar xilose lisina desoxicolato as colônias apresentam-se transparentes, amareladas passando para cor-de-rosa escuro, com ou sem centro negro (7).

Amostras que desenvolvem colônias não características nos meios HE e XLD são descartadas. As demais colônias são transferidas para os meios de triagem LIA e TSI. Colônias que apresentam reações bioquímicas características no LIA e no TSI são repicadas para as provas bioquímicas, enquanto as que não apresentam reações características são descartadas (amostras negativas) (7). 
No meio de triagem LIA as reações positivo-suspeitas são: rampa alcalina e fundo alcalino ou ácido (amarelo); o meio pode ainda apresentar-se enegrecido devido a formação de $\mathrm{H}_{2} \mathrm{~S}$. No meio de triagem TSI as colônias normalmente apresentam rampa alcalina (vermelha) e fundo ácido (amarelo); raramente podem apresentar reação ácido/ácido além de haver ou não formação de $\mathrm{H}_{2} \mathrm{~S}$ e gás (7).

Nas provas bioquímicas, as reações são variáveis e específicas para cada sorotipo de Salmonella, porém a grande maioria apresenta reação positiva para as provas de gás sulfídrico $\left(\mathrm{H}_{2} \mathrm{~S}\right)$, glicose, gás, descarboxilação da lisina, descarboxilação da ornitina, motilidade, citrato e rhamnose e negativas para desaminação do triptofano, lactose e produção de indol (7).

A obtenção de resultado negativo no BIND test rápido indica que a amostra é negativa para Salmonella e o resultado positivo deve ser confirmado mediante métodos padronizados de identificação (5).

\subsection{ETAPA 2}

Na Tabela 2 estão apresentados os resultados obtidos pelo método cultural clássico comparado ao BIND test, para as doze amostras semeadas, podendo-se observar que os resultados foram similares em ambos.

O método cultural clássico necessita longo período de tempo (cerca de 5 dias) para que sejam realizadas todas as etapas para a detecção de Salmonella. A presença de cepas com características atípicas e de colônias de outras enterobactérias com características semelhantes à das Salmonellas dificultam a triagem na etapa do plaqueamento seletivo, exigindo do analista maior experiência profissional.

Tratando-se de método rápido para triagem de Salmonella, a amostra negativa pode ter seu laudo completado em até 24 horas pelo BIND test. A ação de bacteriófago específico para Salmonella elimina o problema de cepas atípicas, porém a existência de reações cruzadas com outras enterobactérias também está presente, pois os resultados indicaram interferência no teste na presença de bactérias do grupo Citrobacter. Quando o resultado da triagem é positivo torna-se técnica mais trabalhosa, pois dispensa para cada amostra muito tempo para realização da técnica apropriada. As amostras positivas devem ser confirmadas pelas provas bioquímicas, o que encarece e aumenta o tempo de análise. 


\section{TABELA 2 - RESULTADOS OBTIDOS PELO MÉTODO CULTURAL CLÁSSICO E PELO BIND TEST PARA AS DOZE AMOSTRAS SEMEADAS (ETAPA 2)}

\begin{tabular}{|c|c|c|c|}
\hline \multicolumn{2}{|c|}{ Método Cultural Clássico } & \multicolumn{2}{|c|}{ BIND Test } \\
\hline Amostras & $\begin{array}{c}\text { Identificação } \\
\text { bioquímica }\end{array}$ & Triagem & $\begin{array}{c}\text { Identificação } \\
\text { Bioquímica }\end{array}$ \\
\hline Farinha de trigo A & $\begin{array}{c}\text { Enterobacter sp } \\
\text { Citrobacter sp }\end{array}$ & 8/8 (positivo) & $\begin{array}{c}\text { Enterobacter sp } \\
\text { Citrobacter sp }\end{array}$ \\
\hline Farinha de trigo $\mathrm{B}$ & Enterobacter sp & 7/8 (negativo) & Negativo \\
\hline Farinha de trigo $\mathrm{C}$ & $\begin{array}{c}\text { Citrobacter } s p \\
\text { Hafnia } s p \\
\end{array}$ & 8/4 (positivo) & $\begin{array}{c}\text { Citrobacter } s p \\
\text { Hafnia } s p \\
\end{array}$ \\
\hline Farinha de trigo D & $\begin{array}{c}\text { Citrobacter sp } \\
\text { Hafnia sp }\end{array}$ & 8/8 (positivo) & $\begin{array}{c}\text { Citrobacter sp } \\
\text { Hafnia sp }\end{array}$ \\
\hline Farinha de trigo E & Citrobacter $s p$ & 6/3 (positivo) & Citrobacter $s p$ \\
\hline Farinha de trigo $\mathrm{F}$ & $\begin{array}{c}\text { Enterobacter sp } \\
\text { Salmonella sp }\end{array}$ & 5/3 (positivo) & $\begin{array}{c}\text { Enterobacter sp } \\
\text { Salmonella sp }\end{array}$ \\
\hline Farinha de trigo $\mathrm{G}$ & Escherichia coli & 3/4 (negativo) & Negativo \\
\hline Farinha de trigo $\mathrm{H}$ & $\begin{array}{l}\text { Escherichia coli } \\
\text { Salmonella sp }\end{array}$ & 4/3 (positivo) & $\begin{array}{c}\text { Escherichia coli } \\
\text { Salmonella sp }\end{array}$ \\
\hline Carne moída & $\begin{array}{c}\text { Escherichia coli } \\
\text { Salmonella sp }\end{array}$ & 8/6 (positivo) & $\begin{array}{c}\text { Escherichia coli } \\
\text { Salmonella sp } \\
\end{array}$ \\
\hline Lingüiça de porco & Enterobacter sp & 1 (negativo) & Negativo \\
\hline Ovo em pó & Citrobacter sp & 3/1 (positivo) & Citrobacter sp \\
\hline Ovo com casca & Negativo & 0 (negativo) & Negativo \\
\hline
\end{tabular}

A Tabela 3 evidencia diferença significativa entre os dois métodos antes da identificação bioquímica, porém, demonstra concordância entre os resultados finais obtidos por ambos os métodos.

Os métodos apresentam características muito semelhantes quanto à recuperação de células, especificidade e diferenciação, chegando-se a resultados finais idênticos. A diferença fundamental, neste caso, baseia-se no procedimento técnico seguido em cada metodologia. O método cultural clássico, desde que o profissional tenha experiência, pode ser executado sem dificuldades, restringindo-se a desvantagem no prazo de análise.

O BIND Test, para amostras com resultado negativo já na etapa da triagem reduz o tempo analítico para 24 horas, não exigindo experiência do profissional, porém para amostras cuja triagem for positivo-suspeita o tempo exigido e a experiência profissional assemelham-se ao método cultural clássico. 


\section{TABELA 3 - COMPARAÇÃO DOS RESULTADOS OBTIDOS PELOS DOIS MÉTODOS DE PESQUISA PARA TODAS AS AMOSTRAS ANALISADAS (ETAPA 1 e 2)}

\begin{tabular}{l|c|c|c}
\hline \multicolumn{1}{c}{ Amostras } & $\begin{array}{c}\text { Método Cultural } \\
\text { Clássico }\end{array}$ & \multicolumn{2}{c}{ BIND Test } \\
\hline Sesquisa de & Triagem & $\begin{array}{c}\text { Pesquisa de } \\
\text { Salmonella sp }\end{array}$ \\
\hline Cepa de S. aureus & Negativa & Negativa & Negativa \\
\hline Cepa de E. aerogenes & Negativa & Negativa & Negativa \\
\hline Cepa de C. freundii & Negativa & Positiva & Negativa \\
\hline Cepa de E. coli & Negativa & Negativa & Negativa \\
\hline Cepa de S. enteritidis & Positiva & Positiva & Positiva \\
\hline $\begin{array}{l}\text { Mistura das cepas c/ } \\
\text { Salmonella }\end{array}$ & Positiva & Positiva & Positiva \\
\hline $\begin{array}{l}\text { Mistura de cepas } \\
\text { s/Salmonella }\end{array}$ & Negativa & Positiva & Negativa \\
\hline Água peptonada & Negativa & Negativa & Negativa \\
\hline Caldo tetrationato & Negativa & Negativa & Negativa \\
\hline Farinha de trigo a & Negativa & Positivo & Negativa \\
\hline Farinha de trigo b & Negativa & Negativo & Negativo \\
\hline Farinha de trigo c & Negativa & Positivo & Negativa \\
\hline Farinha de trigo d & Negativa & Positivo & Negativa \\
\hline Farinha de trigo e & Negativa & Positivo & Negativa \\
\hline Farinha de trigo f & Positiva & Positivo & Positiva \\
\hline Farinha de trigo g & Negativa & Negativo & Negativo \\
\hline Farinha de trigo h & Positiva & Positivo & Positiva \\
\hline Carne moída & Positiva & Positivo & Positiva \\
\hline Lingüiça de porco & Negativa & Negativo & Negativa \\
\hline Ovo em pó & Negativa & Positivo & Negativa \\
\hline Ovo com casca & Negativo & Negativo & Negativo \\
\hline & & &
\end{tabular}

\section{CONCLUSÃO}

Comprovou-se a concordância de resultados entre os métodos, sendo que ambos apresentam vantagens e desvantagens. O método cultural clássico é muito seletivo e específico, porém é menos sensível, mais demorado e exige experiência dos técnicos para observação das características dos microrganismos, enquanto o BIND Test é mais rápido para amostras negativas. 


\begin{abstract}
This work is aimed to evaluate two survey methods for Salmonella in food, by means of simple comparison tests between the methods applied. The project was divided in two stages: the first, accomplished with standard strains, was aimed to verify the specificity of the methods, whereas the second part made the confrontation of the results obtained. The methods used were the Classic Cultural Method, indicated by AOAC, FDA, and by Brazilian Legislation as the chosen method for the research of Salmonella, and the BIND fast test, not mentioned as a method of common use, but already accepted by AOAC. The results demonstrated that there were no differences among the results presented by both methods, being the selection of applicable methodology up to the laboratories.
\end{abstract}

\title{
REFERÊNCIAS BIBLIOGRÁFICAS
}

1 APPCC na qualidade e segurança microbiológica de alimentos: análises de perigos e pontos críticos de controle para garantir a qualidade e a segurança microbiológica de alimentos. São Paulo : Varela, 1997. $377 \mathrm{p}$.

2 BRASIL. Ministério da saúde. Portaria n. 451 de 19 de setembro de 1997. Aprova e oficializa princípios gerais para o estabelecimento de critérios e padrões microbiológicos para alimentos. Diário Oficial [da República Federativa do Brasil], Brasília, 2 de julho de 1998. Seção 1.

3 FLOWERS, K. S. et al. Salmonella. In: APHA. Compendium of methods for the microbiological examination of foods. 3.ed. Washington, 1992. p. 371-422 (Chapter 25).

4 FRAZIER, W. C., WESTHOFF, D. C. Microbiologia de los alimentos. 4.ed. Zaragoza : Acribia, 1993. p. 556-564 (Cap. 24).

5 IDEXX Laboratories, Inc. BIND: rapid assay kit for Salmonella. Maine, USA, [1997]. $12 \mathrm{p}$.

6 JAY, James M. Microbiologia moderna de los alimentos. 3.ed. Zaragoza : Acribia, 1994. p. 651-668 (Cap. 22 ).

7 SILVA, Neusely et al. Manual de métodos de análise microbiológica de alimentos. São Paulo : Varela, 1997. p 41-52 (Cap. 5).

8 WALLACE, H. A. et al. Salmonella. In: FDA. Bacteriological analytical manual (BAM). 8.ed. Washington, 1995. p. 5.01 a 5.20 (Chapter 5). 